\title{
Compreensão de expressões idiomáticas em período de aquisição da linguagem
}

\author{
Idiom comprehension in the language acquisition period
}

\author{
Maity Siqueira \\ Universidade Federal do Rio Grande do Sul - Porto Alegre, RS, Brasil \\ Sergio Duarte Junior \\ Bitácora Centro de Neuropsicologia - Porto Alegre, RS, Brasil \\ Laura Baiocco Pereira \\ Caroline Girardi Ferrari \\ Nichele Lopes \\ Universidade Federal do Rio Grande do Sul - Porto Alegre, RS, Brasil
}

$\diamond$

\begin{abstract}
Resumo: São muitos os estudos sobre a compreensão de expressões idiomáticas. Entretanto, ainda são raros os trabalhos sobre o tema no desenvolvimento da linguagem em língua portuguesa. Este artigo tem por objetivo apresentar a aplicação e os resultados de uma tarefa de compreensão de expressões idiomáticas em 270 participantes em três faixas etárias (crianças, adolescentes e adultos). A tarefa é composta por seis itens: sentenças seguidas de uma pergunta aberta e uma pergunta fechada. A comparação das respostas nos três grupos indica um aumento gradual na compreensão de expressões idiomáticas. Além da idade, discute-se a implicação das variáveis linguísticas contexto, transparência, metaforicidade e familiaridade na compreensão do fenômeno. As análises sugerem que esse fenômeno complexo deve ser estudado levando em conta todos esses aspectos.
\end{abstract}

Palavras-chave: Expressões idiomáticas; Compreensão de linguagem figurada; Linguística cognitiva; psicolinguística

\begin{abstract}
There are already a bulk of studies addressing idiom comprehension. However, developmental studies testing idiom comprehension in Portuguese are rare. This paper aims at presenting the results of an idiom comprehension task with 270 participants in three age groups (children, adolescents and adults). The task consists of six items: sentences followed by an open-ended question and a dichotomous one. A comparison between the three groups indicates a gradual increase in idiom comprehension. Besides age, linguistic variables such as context, transparency, metaphoricity and familiarity in the comprehension of idioms are discussed. The analyses suggest that this complex phenomenon should be studied considering all those aspects.
\end{abstract}

Keywords: Idioms; Figurative language comprehension; Cognitive linguistics; Psycholinguistics

\section{Introdução}

A compreensão das expressões idiomáticas (EI) por adultos tem sido estudada em diversas línguas há bastante tempo. Pesquisas que consideram esse fenômeno na aquisição de linguagem, entretanto, só se desenvolveram recentemente, principalmente nas línguas inglesa, italiana, francesa e no mandarim. Neste artigo, apresentamos os resultados de um estudo que faz uma análise da compreensão de EI por crianças em idade escolar em língua portuguesa, comparada com a de adolescentes e adultos de uma mesma comunidade linguística. Com isso, pretendemos contribuir para os estudos em aquisição da linguagem figurada.

É possível identificar duas visões um tanto antagônicas na literatura sobre expressões idiomáticas. A primeira é a visão tradicional, que trata o fenômeno como sendo exclusivamente linguístico. A outra visão, adotada aqui, é a da Linguística Cognitiva (LC), que trata as EI não só como um fenômeno linguístico, mas também como um recurso cognitivo. 
$\mathrm{Na}$ abordagem tradicional, as EI são definidas como expressões linguísticas cujo significado não pode ser depreendido somente através da soma dos seus constituintes, ou seja, composicionalmente. A Linguística Cognitiva, por outro lado, define EI como construções figuradas convencionalizadas, consideravelmente fixas com duas ou mais palavras, que têm uma função primariamente discursiva e que podem apresentar idiossincrasias (LANGLOTZ, 2006). Ainda que tal definição seja um tanto vaga, nos parece mais completa do que a definição tradicional, uma vez que vai além dos aspectos sintáticos e semânticos e inclui a função discursiva, pragmática, e suas idiossincrasias, o que de certa forma dá conta da multiplicidade de aspectos que caracterizam uma EI.

Consideramos que explicar o fenômeno somente através de uma de suas características, a da composicionalidade, não é suficiente para dar conta da sua complexidade, por várias razões. A primeira razão é que as EI se encontram em um continuum que vai de expressões muito opacas a outras muito transparentes, passando por aquelas que são parcialmente opacas e parcialmente transparentes. A expressão 'quebrar um galho', por exemplo, está na ponta mais opaca do continuum, uma vez que o significado literal das palavras componentes não fornece pistas sobre seu sentido figurado, o de ajudar. A expressão 'pirar na batatinha', por sua vez, é um exemplo de expressão mais transparente, uma vez que pirar dá uma boa pista sobre o sentido figurado da expressão, o de ficar pensando em coisas incoerentes. Uma das contribuições da LC para o estudo da linguagem figurada, de fato, é apontar para a prevalência de um continuum de significação, em várias dimensões, além da composicionalidade.

A segunda razão para a insuficiência dessa definição mais clássica de EI é que ela não leva em conta o fato de que muitas expressões não são arbitrárias, mas sim são motivadas por mapeamentos conceituais. Mapeamentos conceituais metafóricos tais como o identificado entre os domínios INTENSIDADE DE EMOÇÃO e CALOR parecem motivar diversas EI da língua portuguesa, tais como 'jogar um balde de água fria', 'deixar alguém em banho-maria', 'dar um gelo' ou 'soltar fogo pelas ventas'. Outro mapeamento conceitual bastante produtivo em português brasileiro é o que se observa entre os domínios VIDA e JOGO DE FUTEBOL, que motiva as expressões 'dar uma bola fora/dentro', 'colocar alguém para escanteio', 'dar um cartão vermelho', 'pendurar as chuteiras', dentre tantas outras. Assim, a LC introduz a ideia de que muitas EI não são tão arbitrárias quanto podem parecer à primeira vista, ao contrário, muitas são evidentemente motivadas por mapeamentos conceituais metafóricos.
Tal opção teórica obviamente tem implicações para o entendimento da compreensão do fenômeno em fase de aquisição da linguagem. Segundo Gibbs (1991), é possível que as crianças aprendam EI através da análise das partes constituintes da expressão (composicionalmente), mas também é possível que façam conexões entre mapeamentos metafóricos e o significado figurado. Nesse sentido, é razoável supor que mapeamentos altamente convencionais (tal como entre os domínios VIDA e JOGO DE FUTEBOL) podem facilitar a compreensão de expressões derivadas desses mapeamentos. Quando uma mãe diz para um filho que lamenta não ter dado bola pra ele, ela está utilizando uma expressão idiomática corriqueira (que atualiza a metáfora A VIDA É UM JOGO DE FUTEBOL) para dizer que lamenta não ter lhe dado muita atenção.

Não são conhecidos estudos que verifiquem empiricamente a influência dos mapeamentos metafóricos no nível de compreensão de EI por crianças. Conforme veremos na próxima seção, as dimensões das EI mais investigadas são a transparência, o contexto e a familiaridade.

Assim como há EI com diferentes níveis de convencionalidade, também há expressões com diferentes níveis de transparência: 'trocar o disco' (para mudar de assunto) é mais transparente do que 'bater as botas' (para morrer). Convencionalidade e transparência são apenas duas das diversas dimensões que influenciam a compreensão das EI por adultos e crianças. Contexto é outra variável que deve ser considerada quando se trata de compreensão de EI. Nas nossas trocas diárias, as expressões são apresentadas tipicamente dentro de um contexto comunicacional, o que geralmente auxilia na compreensão desse tipo de expressão.

Neste trabalho, foram selecionadas seis expressões idiomáticas que não são derivadas de mapeamentos conceituais convencionais, bastante opacas, bastante familiares e apresentadas fora de contexto. Em relação à variável idade, os estudos divergem ao especificar quando as crianças compreendem EI tão bem quanto os adultos, mas são unânimes em afirmar que tal habilidade vai se desenvolvendo gradualmente com o passar dos anos, conforme veremos mais detalhadamente na próxima seção.

\section{Pesquisas experimentais durante o período de aquisição}

Dentre os diversos aspectos estudados relativos à compreensão da linguagem figurada por crianças, o maior consenso é o de que essa é uma habilidade que começa antes do início da idade escolar e que vai se desenvolvendo gradualmente. 
Um dos modelos mais influentes na descrição da ordem de desenvolvimento da linguagem na infância é o Modelo de Elaboração Global (GEM), de Levorato e Cacciari (1995). Nesse modelo, o desenvolvimento da linguagem figurada segue os mesmos parâmetros do desenvolvimento da linguagem como um todo. Segundo as autoras, na primeira fase, o processamento da linguagem é baseado na estratégia de palavra-por-palavra, o que resulta numa interpretação bem literal do discurso. Essa fase seria predominante até os 7 anos de idade. $\mathrm{Na}$ segunda fase, até cerca dos 9 anos, a criança começa a buscar pistas que a levem a uma interpretação não literal e a identificar incongruências entre a literalidade e o contexto. Na terceira fase, dos 10 aos 12 anos, a criança já está bem mais ciente de intenções comunicativas em suas diferentes formas linguísticas. Na quarta fase, que se estende até aproximadamente os 15 anos de idade, a habilidade de utilizar expressões figuradas é quase total, até que, na última fase, essa competência é como a de um adulto, que inclui usar a linguagem figurada com criatividade e consciência metalinguística. De acordo com Cacciari e Padovani (2012), também é importante ressaltar que não há um limite preciso entre essas fases, uma vez que elas podem se sobrepor.

Alguns autores, no entanto, trazem evidências de que a criança compreende a linguagem figurada em um período um pouco anterior àquele indicado por Levorato e Cacciari (1995). Em um experimento com crianças francesas a partir dos 4 anos e 2 meses de idade, Caillies e Le Sourn-Bissaoui (2006) apontam que crianças de 5 anos já são capazes de entender o sentido figurado de expressões transparentes quando situadas em contexto. No mesmo estudo, as autoras apontam que crianças por volta dos 8 anos já entendiam EI opacas. Esses resultados foram corroborados por Le Sourn-Bissaoui et al. (2012). Com base nesses estudos, portanto, o entendimento do fenômeno começa por volta dos 5 anos e depende de outras variáveis.

Paralelamente à idade, os estudos na área indicam que a compreensão de EI envolve variáveis linguísticas que atuam nesse processo. Conforme se pode observar nos estudos descritos a seguir, as dimensões das EI que mais influenciam a compreensão por crianças são a transparência, o contexto e a familiaridade, nesta ordem.

O estudo de Cain, Oakhill e Lemmon (2005) manipulou transparência, contexto, a familiaridade e habilidade leitora. Mais especificamente, os autores investigaram a compreensão de EI muito e pouco transparentes, dentro e fora de contexto por crianças de 9 a 10 anos com muita e pouca habilidade leitora. Os autores concluíram que o processo de entendimento de EI é construído gradualmente conforme as crianças utilizam análises semânticas ou o contexto para compreender os sentidos das expressões. Segundo eles, crianças de 9 e 10 anos já são capazes de analisar EI semanticamente para tentar deduzir seus sentidos não literais.

No que se refere à analisabilidade das EI, o trabalho de Cain et al. (2005) corrobora um estudo mais antigo de Gibbs (1991). O experimento de Gibbs já indicava que mesmo crianças pequenas, alunos da educação infantil e do primeiro ano, entendem com maior facilidade EI decomponíveis, que analisaram o significado parte a parte para determinadas expressões fazerem sentido. Alunos de $3^{\circ}$ e $4^{\circ}$ ano da mesma amostra, por sua vez, já compreendiam tanto EI decomponíveis, quanto não decomponíveis, quando apresentadas contextualmente. Em situações sem contexto, o desempenho dos alunos melhorou nas EI decomponíveis. Ou seja, é possível supor que decomposicionalidade e transparência caminhem juntas em termos de EI e que as crianças se beneficiem desses atributos quando somam o significado das partes para chegar à análise semântica global de uma expressão.

Além de facilitar a compreensão de EI decomponíveis, o contexto também facilita a compreensão de EI ambíguas (ou seja, que possibilitam tanto interpretações literais quanto figuradas) a partir dos 6 anos de idade, segundo Levorato e Cacciari (1992). Em um experimento composto de historinhas, em que os entrevistadores liam para as crianças, com contextos que levavam a interpretações literais ou idiomáticas, o contexto fez com que as crianças rejeitassem a interpretação literal quando a interpretação idiomática era a mais adequada.

O estudo de Laval (2003) analisou as motivações das crianças para escolherem respostas idiomáticas e concluiu que as crianças mais novas entendem EI tipicamente com base no contexto. Aos 6 anos de idade, a grande maioria das respostas idiomáticas (63 das 86) foram baseadas no contexto, mas esse aspecto parece ir deixando de ser tão prevalente ao passo que as crianças crescem. Aos 9 anos de idade, o contexto ainda é o fator mais decisivo na compreensão de EI, mas com uma vantagem menor em relação à familiaridade da expressão linguística. De 99 respostas idiomáticas, 53 basearam-se no contexto, 30 explicitaram conhecimento da convenção linguística e 16 apontaram o cenário da estória presente no teste. Já os adultos, no grupo controle, responderam 86 vezes motivados pela convenção linguística, 42 pelo contexto e duas pelo cenário, num total de 130 respostas idiomáticas. A convenção linguística, portanto, é um fator que vai se tornando mais e mais preponderante à medida que o sujeito amadurece. Lacroix et al. (2010), em um estudo similar, corroboram a importância do contexto para as crianças de 6 a 8 anos e apontam para a convenção linguística como maior motivação para respostas idiomáticas já a partir dos 9 anos. 
Ainda em relação à relevância do contexto para a compreensão de EI por crianças, o estudo de Cacciari e Levorato (1989) corrobora a hipótese de que um contexto detalhado auxilia na compreensão de EI não familiares. Nesse estudo, crianças de séries iniciais que não compreendiam certas EI apresentadas descontextualizadas, chegavam ao sentido figurado das mesmas expressões quando apresentadas dentro de um contexto.

O contexto, além da familiaridade e da idade, também foi manipulado por Hsieh e Hsu (2010) em um estudo do mandarim com crianças de 6, de 9 anos e adultos. Através de uma tarefa com contextos literais e idiomáticos, os autores encontraram evidências de que crianças de 6 anos produzem mais respostas literais do que idiomáticas, independentemente do contexto e da familiaridade. No mesmo estudo, tanto em expressões familiares quanto em não familiares, as crianças de 9 anos e os adultos produziram respostas de acordo com o contexto.

Embora o contexto seja um fator facilitador em crianças com desenvolvimento típico, a relação entre contexto e compreensão de EI nem sempre é tão linear em crianças com algum tipo de alteração em suas funções cognitivas superiores. Norbury (2004) aponta que a habilidade linguística geral sim é fator determinante para a compreensão de EI, mas que crianças e adolescentes com baixa habilidade linguística não se beneficiam do contexto da mesma forma que seus pares com desenvolvimento típico. Seus resultados também indicam que a memória e outros processos cognitivos além da linguagem também podem causar dificuldades na compreensão de EI em textos. Nessa mesma linha de raciocínio, Qualls et al. (2004) argumentam que, no caso de adolescentes com déficits em habilidades linguísticas, apresentar EI em contextos mais longos compromete o entendimento das expressões. A explicação dos autores é que um contexto mais rico requer que esses sujeitos integrem uma grande quantidade de informação para ir além do significado local em busca de um sentido global da expressão, além de terem que atribuir múltiplos significados às palavras e isso demanda um esforço maior do que simplesmente entender uma expressão.

Conforme já foi mencionado, além da transparência e do contexto, a familiaridade é uma variável linguística de interesse nos estudos que abordam a compreensão de EI no desenvolvimento. A familiaridade foi investigada inicialmente por Levorato e Cacciari (1992), no italiano. De acordo com os dados das autoras, a familiaridade não exerce um papel muito importante, exceto para crianças mais novas, que ainda não são capazes de interpretar informações contextuais. Para elas, o efeito da familiaridade parece ser mais local e restrito a facilitar a rejeição da interpretação literal de EI em contextos cotidianos que geralmente enviesam a interpretação idiomática. O estudo de Hsieh e Hsu (2010), no mandarim, como já vimos, corrobora os achados de Levorato e Cacciari no que diz respeito à familiaridade e também na importância do contexto. Os achados de Nippold e colaboradoras (NIPPOLD e RUDZINSKI, 1993; NIPPOLD e TAYLOR, 2002), por outro lado, apontam para a influência da familiaridade na compreensão de EI por crianças e adolescentes falantes de inglês. As autoras explicam tal dissonância nos resultados parcialmente em função das diferenças metodológicas, uma vez que formularam uma tarefa com perguntas abertas, enquanto a das italianas era de múltipla escolha, um fator que certamente facilita a identificação da resposta correta.

Um boa explicação a respeito da relação entre os aspectos idade e variáveis linguísticas foi apresentado por Cain, Oakhill e Lemmon (2006) em seu trabalho com compreensão de EI no inglês britânico. Os autores argumentam que a familiaridade só é um fator relevante quando as crianças já são maiores e conseguem entender realmente o significado idiomático do que ouvem. Em outras palavras, o fato de uma expressão ser familiar para uma criança, por já ter sido ouvida algumas vezes, não garante que essa expressão tenha sido entendida.

Levando em consideração a fundamentação teórica e os estudos experimentais apresentados, nossa hipótese central é de que a compreensão de EI aumenta paralelamente à idade. Neste trabalho, as variáveis linguísticas mencionadas nos diferentes experimentos (transparência, contexto e familiaridade) foram controladas e a variável idade foi manipulada, conforme será detalhado a seguir, no Método.

\section{Método}

\section{Participantes}

O estudo foi constituído por 270 participantes, divididos em três grupos. O Grupo 1 era formado por 139 crianças, com idades variando entre 6 anos e 11 anos e 11 meses $(m=8,8 ; d p=1,5)$. O Grupo 2 era formado por 55 adolescentes, com idades variando entre 12 anos e 17 anos e 11 meses $(m=15,5 ; d p=1,5)$. O Grupo 3 era formado por 76 adultos maiores de 18 anos $(m=36 ; d p=14,1)$. Essa linha de corte para a classificação etária foi feita conforme as diretrizes da American Academy of Pediatrics. A amostra foi composta por estudantes de escolas regulares públicas e privadas de Porto Alegre, de uma universidade federal e por funcionários da mesma universidade, todos selecionados por conveniência. A distribuição por tipo de escola e sexo está apresentada na Tabela 1. 
Tabela 1. Distribuição por tipo de escola e sexo

\begin{tabular}{cccccc}
\hline \multirow{2}{*}{ Grupo } & \multicolumn{2}{c}{ Sexo } & \multicolumn{2}{c}{ Escola } \\
\cline { 2 - 3 } & Masculino & Feminino & Pública & Privada \\
$\mathbf{1}$ & 65 & 74 & 42 & 97 \\
$\mathbf{2}$ & 23 & 32 & 55 & 0 \\
$\mathbf{3}$ & 34 & 42 & não informado \\
\hline
\end{tabular}

Fonte: Elaboração própria.

Como critério de inclusão estabelecemos que os participantes deveriam ser falantes nativos de Português Brasileiro. O critério de exclusão foi a presença de comorbidades sensoriais e/ou cognitivas e de queixa de dificuldade de aprendizagem referidas pela escola (no caso de crianças e adolescentes) ou sem alteração cognitiva ou sensorial aparente (no caso de adultos).

\section{Materiais e procedimentos}

A coleta dos dados foi realizada em uma universidade pública e em duas escolas selecionadas. A aplicação do instrumento foi realizada individualmente, após o consentimento da direção, dos professores (no caso de crianças e adolescentes) e da assinatura do Termo de Consentimento Livre e Esclarecido pelos participantes (adultos) ou por seus responsáveis (crianças ou adolescentes).

O Teste de Compreensão de Expressões Idiomáticas (Siqueira e Marques, no prelo) foi utilizado para a coleta de dados. Esse teste é uma das tarefas do Instrumento de Compreensão de Linguagem Figurada ${ }^{1}$ (que inclui também tarefas de metonímias, metáforas, provérbio e ironia) e é composto por seis EI, apresentadas em sentenças descontextualizadas. A tarefa era responder a duas perguntas (uma aberta e uma fechada) sobre o significado de cada uma das EI.

As perguntas eram lidas por um dos pesquisadores e as respostas eram anotadas por outro pesquisador em um protocolo de respostas. Os resultados foram avaliados da seguinte forma: respostas esperadas receberam um escore 1 , todas as outras respostas receberam um escore 0 . Os participantes poderiam ter um escore de 0 a 12, uma vez que deveriam responder a duas perguntas sobre cada uma das seis EI.

As seis expressões, as sentenças que constituem os itens, as perguntas e as diretrizes para sua correção estão descritas na Tabela 2, abaixo.

\section{Resultados}

\section{Análise quantitativa}

Os dados foram analisados por meio de estatística descritiva e paramétrica, utilizando o programa Statistical Package for Social Sciences (SPSS), versão 18.

Uma análise preliminar identificou o grau de familiaridade de cada umas das seis expressões do Teste de Compreensão de $\mathrm{EI}^{2}$. Os resultados apontaram que o item mais familiar foi a EI 3 (Fazer tempestade em copo d'água) e o menos familiar foi a EI 4 (Sair como um par de vasos), conforme indicado na Tabela 3. Cabe ressaltar que a tarefa de familiaridade foi realizada somente por adultos, sujeitos diferentes daqueles que responderam à tarefa de compreensão de EI.

Tabela 2. Itens do teste e diretrizes para correção

\begin{tabular}{|c|c|c|c|}
\hline EI & Item & Perguntas & Correção \\
\hline Fase de treino X. Quebrar um galho. & $\begin{array}{l}\text { Luisa quebrou um galho para a } \\
\text { Carol. }\end{array}$ & $\begin{array}{l}\text { a) O que a Luisa fez para a Carol? } \\
\text { b) Ela ajudou ou atrapalhou a Carol? }\end{array}$ & $\begin{array}{l}\text { a) Ajudou, fez algo que a outra } \\
\text { precisava ou queria. } \\
\text { b) Ajudou. }\end{array}$ \\
\hline 1. Comprar gato por lebre. & $\begin{array}{l}\text { El } 1 \\
\text { Antonio comprou gato por lebre. }\end{array}$ & $\begin{array}{l}\text { a) O que aconteceu com ele? } \\
\text { b) Ele foi enganado ou não foi } \\
\text { enganado? }\end{array}$ & $\begin{array}{l}\text { a) Foi enganado, trapaceado, } \\
\text { passaram a perna nele. } \\
\text { b) Compra ruim. }\end{array}$ \\
\hline 2. Meter os pés pelas mãos. & $\begin{array}{l}\text { El } 2 \\
\text { Cristina meteu os pés pelas mãos. }\end{array}$ & $\begin{array}{l}\text { a) Como foi a atitude dela? } \\
\text { b) Ela pensou antes de agir ou agiu } \\
\text { sem pensar? }\end{array}$ & $\begin{array}{l}\text { a) Impensada, afoita, ruim, má, } \\
\text { rápida demais. } \\
\text { b) Agiu sem pensar. }\end{array}$ \\
\hline 3. Fazer tempestade em copo d'água. & $\begin{array}{l}\text { El } 3 \\
\text { João fez tempestade em copo d'água. }\end{array}$ & $\begin{array}{l}\text { a) Como ele reagiu? } \\
\text { b) Ele é preocupado ou tranquilo? }\end{array}$ & $\begin{array}{l}\text { a) Mal, brabo, irritado, furioso, se } \\
\text { preocupou demais. } \\
\text { b) Ficou preocupado. }\end{array}$ \\
\hline 4. Sair como um par de vasos. & $\begin{array}{l}\text { El } 4 \\
\text { Ana e Lia saíram como um par de } \\
\text { vasos. }\end{array}$ & $\begin{array}{l}\text { a) Como elas se vestem? } \\
\text { b) As roupas delas são diferentes ou } \\
\text { iguais? }\end{array}$ & $\begin{array}{l}\text { a) Se vestem igual, da mesma } \\
\text { forma, com as mesmas roupas. } \\
\text { b) Roupas são iguais. }\end{array}$ \\
\hline 5. Ser a metade da laranja. & $\begin{array}{l}\text { El } 5 \\
\text { Paulo é a metade da laranja da } \\
\text { Laura. }\end{array}$ & $\begin{array}{l}\text { a) O que Laura sente por Paulo? } \\
\text { b) Ela adora ou detesta ele? }\end{array}$ & $\begin{array}{l}\text { a) Amor, paixão, gosta dele. } \\
\text { b) Adora ele. }\end{array}$ \\
\hline 6. Tomar um chá de cadeira. & $\begin{array}{l}\text { El } 6 \\
\text { Alice tomou um chá de cadeira. }\end{array}$ & $\begin{array}{l}\text { a) O que aconteceu com Alice? } \\
\text { b) Ela esperou muito ou pouco? }\end{array}$ & $\begin{array}{l}\text { a) Esperou muito, por horas, } \\
\text { qualquer evento demorado. } \\
\text { b) Esperou muito. }\end{array}$ \\
\hline
\end{tabular}

Fonte: Elaboração própria. ${ }^{1}$ Em desenvolvimento pelo grupo de pesquisa METAFOLIA, do PPG
Letras, UFRGS.
${ }^{2}$ Foi realizada uma tarefa de familiaridade através de uma escala Likert de
cinco pontos, na qual 1 corresponde a nada familiar e 5 a totalmente familiar. 
Tabela 3. Análise percentual de familiaridade nas respostas 4 e 5

\begin{tabular}{lcccccc}
\hline EI & $\mathbf{1}$ & $\mathbf{2}$ & $\mathbf{3}$ & $\mathbf{4}$ & $\mathbf{5}$ & $\mathbf{6}$ \\
Respostas “4” & 15,05 & 8,96 & 3,94 & 10,04 & 9,32 & 11,11 \\
Respostas “5” & 67,74 & 87,10 & 93,91 & 59,86 & 78,85 & 75,27 \\
Total & 82,79 & 96,06 & 97,85 & 69,90 & 88,17 & 86,38 \\
\hline
\end{tabular}

Fonte: Siqueira e Marques (no prelo).

Uma outra análise preliminar foi a de confiabilidade dos critérios de correção estabelecidos para as perguntas abertas das EI. Os dados utilizados para essa análise foram as correções de seis juízes especialistas, membros do grupo de pesquisa. Todas as respostas em que houve discordância de algum avaliador foram discutidas pelo grupo até se chegar a um consenso. Considerando que o Kappa variou de 0,77 a 1,00 para as primeiras 44 questões corrigidas $(p<0,001)$, julgamos que os critérios estavam bem calibrados e as correções subsequentes foram realizadas de forma independente.

A análise seguinte foi a do desempenho por idade no Teste de Compreensão de Expressões Idiomáticas. Nossa hipótese central, a de que a compreensão de EI aumenta com o passar dos anos, foi corroborada, uma vez que verificamos que há uma correlação positiva entre idade e compreensão de EI (como indicado na Figura 1).

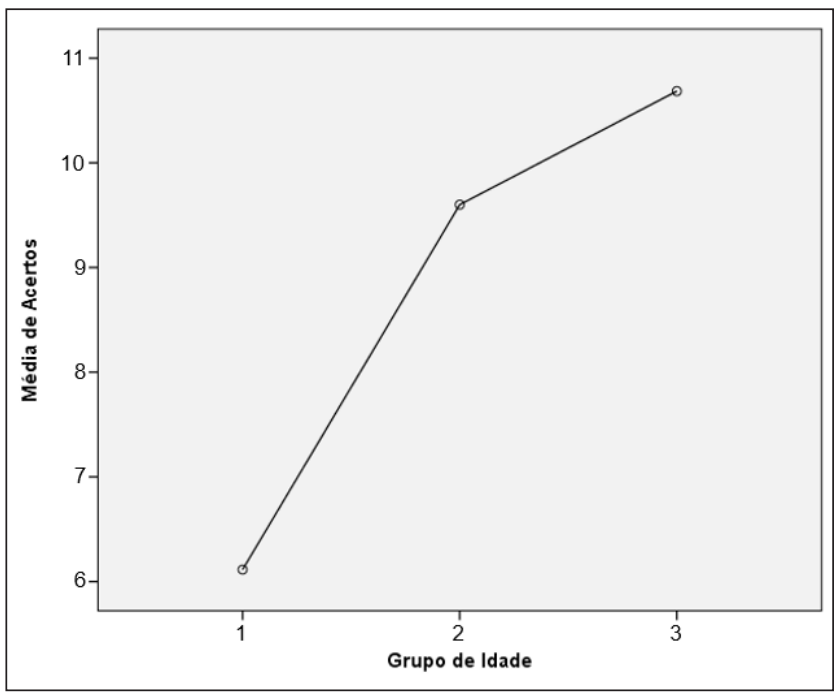

Fonte: Elaboração própria.

Figura 1. Média de acertos (perguntas abertas e fechadas) por grupo de idade

Uma análise para verificar o desempenho por faixa etária foi feita a seguir. Os resultados de uma análise de variância (ANOVA) indicaram um efeito principal de idade $(\mathrm{p}<0.001)$ na compreensão de EI. Uma análise post hoc (teste de Tuckey) mostrou que há diferença significativa entre todos os grupos $(\mathrm{p}<0.001)$, sugerindo evidências de sensibilidade do instrumento ao diferenciar os grupos considerando a variável idade.

De forma a detalhar o desempenho dos participantes, um Teste $\mathrm{T}$ foi realizado para verificar se $\mathrm{o}$ número de acertos das respostas abertas e fechadas difere entre os grupos. Conforme é possível observar na Tabela 4, as perguntas fechadas tiveram maior número de acertos quando comparadas com as perguntas abertas em todas as idades. A análise da diferença entre perguntas abertas e fechadas por grupo também mostrou uma diferença estatisticamente significativa $(p<0,001)$ em todas as faixas etárias. Conforme o esperado, os escores mais altos foram verificados nas perguntas fechadas, dicotômicas, do que nas perguntas abertas. Cabe lembrar que, neste contexto, escore alto significa melhor desempenho.

Tabela 4. Comparação entre idades por tipo de pergunta

\begin{tabular}{lcccc}
\hline Variáveis & $\begin{array}{c}\text { Crianças } \\
\text { Média } \pm D P\end{array}$ & $\begin{array}{c}\text { Adolescentes } \\
\text { Média } \pm D P\end{array}$ & $\begin{array}{c}\text { Adultos } \\
\text { Média } \pm D P\end{array}$ & p $^{*}$ \\
Total El & $6.11 \pm 2.16$ & $9.59 \pm 1.49$ & $10,67 \pm 1.17$ & $<0.001$ \\
Total El Aberta & $1.86 \pm 1.09$ & $4.02 \pm 1.07$ & $4.94 \pm 0.92$ & $<0.001$ \\
Total El Fechada & $4.25 \pm 1.35$ & $5.58 \pm 0.68$ & $5.74 \pm 0.52$ & $<0.001$ \\
\hline
\end{tabular}

Fonte: Elaboração própria.

Observamos, portanto, um aumento na média de respostas e uma queda nos valores de desvio padrão com o aumento da idade, tanto nas perguntas abertas quanto nas perguntas fechadas, o que corrobora a hipótese central deste trabalho, de que a compreensão de EI evolui com o desenvolvimento.

Quando avaliado o desempenho por item, considerando as perguntas abertas e fechadas conjuntamente, verificamos que o item com mais acertos ( $86 \%$ e $95 \%$ para aberta e fechada, respectivamente) foi o número 5 , que atualiza a expressão idiomática 'ser a metade da laranja'. O menor percentual de acertos para a pergunta aberta e fechada ( $27 \%$ e $69 \%$, respectivamente) foi verificado nos itens 1 e 4, que atualiza as expressões idiomáticas 'comprar gato por lebre' e 'sair como um par de vasos'. Essas diferenças foram estatisticamente significativas $(p<0,001)$ para ambos os tipos de pergunta (aberta e fechada) (Figura 2).

Por fim, foi realizada uma análise da relação entre o nível de familiaridade das expressões e o desempenho em cada EI do teste por cada um dos grupos, descrita na Tabela 5. Os resultados indicam que não há evidência de relação entre essas variáveis, uma vez que as EI mais familiares não foram as mais bem compreendidas por nenhuma das idades. 


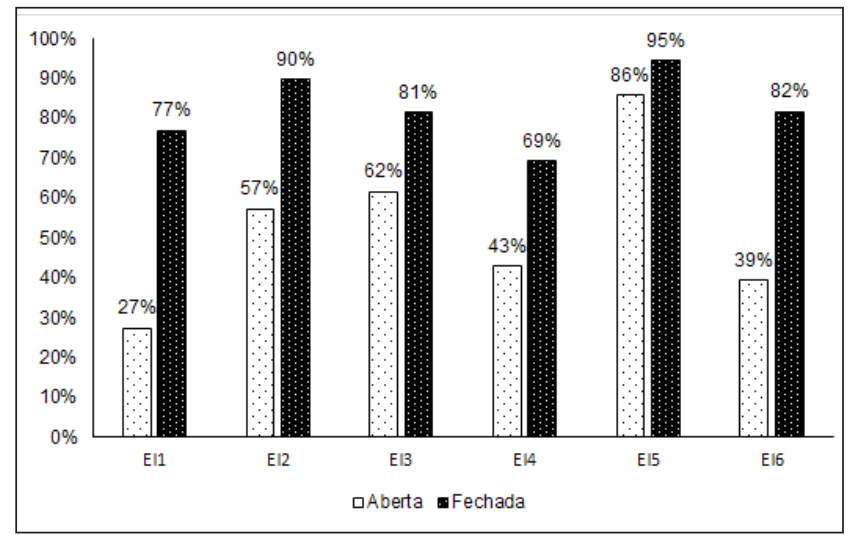

Fonte: Elaboração própria.

Figura 2. Percentual de acertos nas perguntas abertas e fechadas

Tabela 5. Nível de familiaridade das EI e acertos por idade

\begin{tabular}{cccccc}
\hline EI & Familiaridade & $\begin{array}{c}\text { Acertos } \\
\text { Geral }\end{array}$ & $\begin{array}{c}\text { Acerto } \\
\text { Criança }\end{array}$ & $\begin{array}{c}\text { Acerto } \\
\text { Adolescente }\end{array}$ & $\begin{array}{c}\text { Acerto } \\
\text { Adulto }\end{array}$ \\
$\mathbf{1}$ & $83 \%$ & $52 \%$ & $36 \%$ & $52 \%$ & $82 \%$ \\
$\mathbf{2}$ & $96 \%$ & $74 \%$ & $60 \%$ & $85 \%$ & $89 \%$ \\
$\mathbf{3}$ & $98 \%$ & $72 \%$ & $53 \%$ & $93 \%$ & $91 \%$ \\
$\mathbf{4}$ & $69 \%$ & $56 \%$ & $34 \%$ & $79 \%$ & $81 \%$ \\
$\mathbf{5}$ & $88 \%$ & $90 \%$ & $84 \%$ & $98 \%$ & $96 \%$ \\
$\mathbf{6}$ & $86 \%$ & $61 \%$ & $38 \%$ & $74 \%$ & $94 \%$ \\
\hline
\end{tabular}

Fonte: Elaboração própria.

\subsection{Análise qualitativa}

Tanto os estudos apresentados na seção de pesquisas experimentais quanto os resultados descritos na seção 4.1 apontam para um aumento contínuo de compreensão no decorrer do desenvolvimento. Nesta seção, será apresentada uma análise qualitativa das respostas das crianças, com o intuito de verificar as estratégias utilizadas pelos participantes até chegar na compreensão idiomática das expressões.

A fim de facilitar a leitura, retomamos aqui a apresentação das seis EI incluídas neste estudo (Tabela 6).

Tabela 6. Expressões idiomáticas

\begin{tabular}{ll}
\hline El 1 & Antonio comprou gato por lebre. \\
El 2 & Cristina meteu os pés pelas mãos. \\
El 3 & João fez tempestade em copo d'água. \\
El 4 & Ana e Lia saíram como um par de vasos. \\
El 5 & Paulo é a metade da laranja da Laura. \\
El 6 & Alice tomou um chá de cadeira. \\
\hline
\end{tabular}

Fonte: Elaboração própria

A análise das respostas dos sujeitos mais novos da nossa amostra, as crianças de até 7 anos, indicou o predomínio da literalidade, ou seja, a maioria das crianças não interpretou as EI de forma figurada. Embora tenhamos um número pequeno de sujeitos nesta faixa etária, tais resultados podem servir de indicadores que reafirmam a primeira fase apresentada no GEM (LEVORATO \& CACCIARI, 1995), como demonstrado nos exemplos abaixo:

EI 2 (suj. 433, masc., 6a8m):

Foi bem difícil, já tentei fazer isso.

EI 3 (suj. 26, fem., 6a5m):

Tinha um buraco e o raio foi no copo.

EI 6 (suj. 25, fem., 6a):

Ficou mal e vomitou.

Entretanto, algumas crianças de 6 anos já conseguem, de certa forma, atingir o sentido figurado de expressões, como vemos a seguir:

\section{EI 3 (suj. 25, fem., 6a):}

Não agiu bem, fez alguma coisa que não podia fazer.

EI 3 (suj. 405, fem., 6a9m):

Quando uma pessoa chora por nada.

Ainda segundo o GEM, a partir dos 7 anos (mais especificamente, crianças entre 7 e 9 anos) começam a buscar pistas que levem a uma interpretação menos literal. Nossos dados também sugerem que, nesta faixa etária, muitas crianças já percebem que uma interpretação literal das expressões não é adequada e tentam interpretá-las de forma que seja coerente, o que não significa que eles cheguem à resposta esperada. As respostas dadas pelos sujeitos 440 e 336 sugerem que esses participantes interpretam as EI através de uma análise das partes constituintes da expressão, ou seja, composicionalmente.

\section{EI 2 (suj. 440, masc., 8a3m):}

Trocou uma coisa por outra.

EI 6 (suj. 386, fem., 8a7m):

Ficou sentada um tempão esperando na cadeira.

Das crianças entrevistadas, de fato, poucas conseguiram atingir a resposta esperada nesta faixa etária. $\mathrm{Na}$ grande maioria das vezes, essas análises semânticas levaram a interpretações figuradas que não são exatamente esperadas para as EI em questão (sujeitos 385, 361 e 2) ou a interpretações limites entre o literal e o figurado (sujeito 373).

\section{EI 1 (suj. 385, masc., 8a8m):}

Comprou uma lebre por bastante dinheiro.

EI 3 (suj. 361, fem., 8a4m):

Ficou com raiva e bebeu água. 
EI 4 (suj. 2, fem., 7allm):

Acho que de marrom e verde.

EI 6 (suj. 373, fem., 9a7m):

Ficou sentada.

Contrariando o modelo de Levorato e Cacciari (1995), entretanto, nossos dados mostram que algumas crianças de 7 a 9 anos ainda interpretam as EI de maneira bastante literal, como vemos nos exemplos abaixo:

EI 1 (suj. 387, masc., 8a10m):

Trocou o gato por lebre de estimação.

EI 2 (suj. 397, fem., 8a):

Comeu com o pé e colocou o sapato na mão.

EI 3 (suj. 331, fem., 9a2m):

Feliz porque conseguiu fazer uma tempestade com pouca água.

EI 4 (suj. 451, fem., 7alm):

Se vestiram como uma privada ${ }^{3}$.

A análise das respostas dos participantes que tinham em torno de 10 anos de idade, apontam que, de fato, por essa época a habilidade de compreensão de EI já está bastante desenvolvida. Isso pode ser explicado tanto por um desenvolvimento de capacidades pragmáticas gerais, ou seja, de leitura de intenções comunicativas (TOMASELLO, 2003) e inclusão de informações contextuais, quanto pela exposição das crianças a mais expressões. Com o passar dos anos, as crianças vão sendo mais expostas às EI através de materiais escritos e da linguagem oral, na escola e fora dela e vão entendendo melhor o sentido de expressões bastante utilizadas em certos contextos discursivos. Como podemos observar nos exemplos abaixo, algumas crianças dessa idade simplesmente deram o significado idiomático (sujeito 422), enquanto outras usaram um contexto específico (sujeito 415) para dar sua resposta.

\section{EI 2 (suj. 415, fem., 9a10m):}

Se confundiu com alguma coisa. O Chico Bento tinha que dar comida pro porco e pra galinha, mas deu a comida da galinha pro porco e a do porco pra galinha.

EI 3 (suj. 452, fem., 10alm):

Ficou irritado com alguma coisa.

EI 4 (suj. 422, fem., 10a3m):

Iguais.

Apesar da maioria das crianças dessa faixa etária já demonstrar compreender que as EI tem um sentido figurado e que, portanto, elas devem buscar um sentido

\footnotetext{
3 Alguns participantes interpretaram a palavra "vaso" polissemicamente, atribuindo o significado de "vaso sanitário".
}

diferente do literal, ainda é possível observar que algumas crianças mais velhas e até mesmo adolescentes ainda fazem uma análise bastante literal de partes ou de toda a expressão, como nos exemplos a seguir.

EI 4 (suj. 401, fem., 11a7m):

São flores.

EI 5 (suj. 348, 17a):

Um sentimento com gosto de laranja.

EI 6 (suj. 402, fem., 10a8m):

Pegou uma cadeira, espremeu e colocou no chá.

A possibilidade de decompor as expressões e analisar suas partes parece ser um fator facilitador para crianças de todas as idades, mas esse fator fica mais evidente nas respostas de crianças com idade mais avançada. Algumas das respostas evidenciam o quanto o significado literal das palavras que compõem uma expressão pode ajudar a chegar ao sentido figurado. Particularmente na EI 5 (ser a metade da laranja), muitos mencionaram a ideia de unificação de duas partes.

\section{EI 5 (suj. 391, masc., 9a8m):}

Braço direito e braço esquerdo. Sempre ajuda, sempre defende.

EI 5 (suj. 411, fem., 11a9m):

Como se fossem completar a laranja, sente amor.

Um outro fator que merece ser tratado aqui é o da relação entre as diferentes figuras de linguagem. A relação de interesse para este estudo é entre EI e metáfora, por isso nos deteremos somente nela. Conforme já foi mencionado na introdução, a LC argumenta que muitas EI não são arbitrárias, mas sim derivadas de mapeamentos metafóricos conceituais. Esse fator foi controlado nos itens do teste (foram selecionadas EI que supostamente não atualizam mapeamentos metafóricos), justamente para separar a habilidade de compreender EI da habilidade de compreender metáforas, que julgamos habilidades distintas, apesar de relacionadas. Como podemos ver nas respostas abaixo, os próprios participantes utilizaram metáforas em suas respostas. A produção espontânea de metáforas linguísticas foi observada em diferentes itens, nas diferentes idades, mas esse tipo de resposta foi mais frequente na EI 2 ('botar os pés pelas mãos' e nas respostas de participantes que tinham 8 anos de idade ou mais.

Todas as respostas abaixo atualizam a metáfora conceitual IMPORTÂNCIA É TAMANHO. A partir dessas respostas, podemos supor que, apesar de 'fazer tempestade em copo d'água' não ser uma atualização tão explícita dessa metáfora conceitual, de alguma forma remete a ela. 
EI 2 (suj. 396, fem., 8a8m):

Uma coisa pequena transformou em grande.

EI 2 (suj. 403, masc., 11a3m):

Fez uma confusão, falou uma coisa e fez uma confusão imensa. Fez uma coisa pequena ficar grande.

EI 2 (suj. 314, masc., 17a):

Entendeu um pequeno problema como maior.

EI 2 (suj. 309, masc., 23a):

Aumentou muito o problema que era uma coisa simples.

A análise qualitativa deste estudo aponta para um aumento gradual da capacidade de compreensão de EI no desenvolvimento. Em geral, nossos resultados estão em consonância com as faixas etárias sugeridas pelo modelo de Levorato e Cacciari (1995), bem como apontam para uma sobreposição das habilidades nos diferentes períodos e não indicam uma idade ou faixa etária específica na qual a habilidade de compreender EI já está plenamente desenvolvida.

\section{Discussão}

O objetivo principal deste estudo foi o de verificar se a idade tem influência sobre a compreensão de expressões idiomáticas. Os resultados obtidos indicam que quanto maior a idade do participante, mais conhecimento ele terá a respeito de EI. Além da idade, outros fatores, como contexto, transparência, metaforicidade e familiaridade também estão envolvidos na compreensão do mesmo fenômeno linguístico.

$\mathrm{Na}$ tarefa desenvolvida para este estudo, o contexto e a transparência foram dois dos fatores controlados. Cabe esclarecer aqui que a tarefa de compreensão de EI compõe o Teste de Linguagem Figurada, que inclui tarefas de compreensão de metonímia, metáfora, provérbio e ironia. Com relação ao contexto, os itens foram apresentados descontextualizados, a fim de padronizar com as demais tarefas presentes no teste de linguagem figurada. Com relação ao grau de opacidade, foram selecionadas expressões consideradas pouco transparentes.

O fator metaforicidade foi controlado através da seleção de expressões que não atualizam metáforas conceituais. Ainda assim, como vimos, algumas crianças produziram metáforas linguísticas nas suas respostas. $\mathrm{O}$ fato de que os participantes apresentavam atualizações metafóricas na fala evidencia a capacidade de produzir linguagem figurada e exemplifica o postulado da LC de que algumas expressões atualizam ou remetem a certos mapeamentos metafóricos.

Quanto à familiaridade, apesar de nossa intuição e de alguns estudos apontarem para a relevância desse fator, nossos dados mostram que esse não se mostrou uma variável que causasse algum impacto na compreensão das
EI selecionadas. O teste de familiaridade indicou que as duas expressões julgadas mais familiares pelos adultos da comunidade linguística pesquisa foram 'tempestade em copo d'água' e 'meter os pés pelas mãos'. No entanto, a expressão com melhores índices de desempenho nas três faixas etárias foi 'a metade da laranja', o que sugere que não há uma relação direta entre familiaridade e compreensão. Ao invés disso, entendemos que diferentes variáveis influenciam na compreensão do fenômeno. De fato, com exceção do contexto, todas as outras dimensões aqui mencionadas apontam para a existência de um continuum de significação. Apesar de a variável manipulada idade ter sido segmentada de forma categórica, os dados mostram que o aumento de compreensão se dá de forma gradual. Apesar de termos selecionado expressões bastante opacas, uma maior transparência foi verificada na expressão 'metade da laranja'; ainda que tenhamos selecionado expressões não derivadas de metáforas conceituais, a expressão 'tempestade em copo d'água' remeteu ao mapeamento IMPORTÂNCIA É TAMANHO; a despeito de termos selecionado expressões bastante familiares, a expressão 'par de vasos' não era tão conhecida quanto as outras.

Uma possível limitação deste estudo foi não considerar a origem das crianças em termos do tipo de escola que frequentam, pública ou privada. A literatura mostra que a proficiência leitora está diretamente ligada à compreensão de linguagem figurada (CAIN et al., 2005), dado que uma maior habilidade leitora melhora o desempenho em um teste de linguagem figurada. Além de manipular o fator tipo de escola, será interessante incluir uma nova faixa etária com crianças mais novas, em idade pré escolar, em pesquisas futuras.

Com este estudo e os resultados aqui apresentados pretendemos contribuir para o estabelecimento de parâmetros tanto para o processo de aquisição de expressões idiomáticas ao longo do desenvolvimento, quanto para novas pesquisas a serem conduzidas sobre o fenômeno.

\section{Agradecimentos}

Os autores agradecem aos bolsistas voluntários de iniciação científica da Universidade Federal do Rio Grande do Sul Fernanda Kettes, Leonardo Cláudio da Rosa, Michelle Braga de Oliveira e Paloma Seibt Jaeger pelo seu trabalho durante as diversas fases deste estudo.

\section{Referências}

CACCIARI, Cristina; LEVORATO, Maria Chiara. Children's comprehension and production of idioms: the role of context and familiarity. Journal of Child Language, v. 19, p. 415-433, 1992. 
CACCIARI, Cristina; LEVORATO, Maria Chiara. The Effects of Different Tasks on the Comprehension and Production of Idioms in Children. Journal of Experimental Child Psychology, v. 60, p. 261-283, 1995.

CACCIARI, Cristina; LEVORATO, Maria Chiara. The effect of semantic analysability of idioms in metalinguistic tasks. Metaphor and Symbol, v. 13, p. 159-177, 1989.

CACCIARI, Cristina; PADOVANI, Roberto. The Development of Figurative Language. In: The Cambridge Handbook of Psycholinguistics. Cambridge: Cambridge University Press, 2012. p. 505-522.

CAILLIES, Stéphanie; LE SOURN-BISSAOUI, Sandrine. Idiom comprehension in French children: A cock-and-bull story. European Journal of Developmental Psychology, v. 3, n. 2, p. 189-206, 2006. DOI: 10.1080/17405620500412325

CAIN, Kate; OAKHILL, Jane; LEMMON, Kate. The relation between children's reading comprehension level and their comprehension of idioms. Journal of Experimental Child Psychology, v. 90, p. 65-87, 2005.

GIBBS, Raymond. Semantic analyzability in children's understanding of idioms. Journal of Speech and Hearing Research, v. 34, p. 613-620, 1991.

HSIEH, Shelley Ching-Yu.; HSU, Chun-Chieh Natalie. Idiom Comprehension in Mandarin-Speaking Children. Journal of Psycholinguistic Research, v. 39, p. 505-522, 2010.

LACROIX, Agnès; AGUERT, Marc; DARDIER, Virginie; STOJANOVIK, Vesna; LAVAL, Virginie. Idiom comprehension in French-speaking children and adolescents with Williams' syndrome. Research in Developmental Disabilities, v. 31, p. 608-616, 2010.

LANGLOTZ, Andreas. Idiomatic Creativity: A cognitivelinguistic model of idiom-representation and idiom-variation in English. Amsterdam: John Benjamins, 2006. p. 339.
LAVAL, Virginie. Idiom comprehension and metapragmatic knowledge in French children. Journal of Pragmatics, v. 35, p. 723-739, 2003.

LE SOURN-BISSAOUI, Sandrine.; CAILLIES, Stéphanie; BERNARD, Stéphane; DELEAU, Michel; BRULÉ, Lauriane. Children's understanding of ambiguous idioms and conversational perspective-taking. Journal of Experimental Child Psychology, v. 112, p. 437-451, 2012.

NIPPOLD, Marilyn; RUDZINSKI, Mishelle. Familiarity and transparency in idiom explanation: A developmental study of children and adolescents. Journal of Speech and Hearing Research, v. 36, p. 728-737, 1993.

NIPPOLD, Marilyn; TAYLOR, Catherine. Judgements of idiom familiarity and transparency: A comparison of children and adolescents. Journal of Speech and Hearing Research, v. 45, p. 384-391, 2002.

NORBURY, Courtenay Frazier. Factors supporting idiom comprehension in children with communication disorders. Journal of Speech, Language and Hearing Research, v. 47, p. 1179-1193, 2004.

QUALLS, Constance Dean; LANTZ, Jennifer; PIETRZYK, Rose; HAMMERA, Carol Scheffner. Comprehension of idioms in adolescents with language-based learning disabilities compared to their typically developing peers. Journal of Communication Disorders, v. 37, n. 4, p. 295-311, 2004.

TOMASELLO, Michael. Constructing a Language: A UsageBased Theory of Language Acquisition. Cambridge, MA: Harvard University Press, 2003.

Recebido: 28 de fevereiro de 2017

Aprovado: 21 de abril de 2017

Contato:

Maity Siqueira <maitysiqueira@hotmail.com> 